\title{
5. Birds on the Wire: Wild sound, informal speech and the emergence of the radio documentary
}

\author{
Tony MacGregor
}

\begin{abstract}
Sound Effect (SFX): The sound of a needle being placed into the groove of an old and worn $78 \mathrm{rpm}$ disc. A low-level rumble, and the hiss and scratch of surface noise, and then the sound of birds - exotic whistles and cluckings, a cacophony of magpie geese and plovers and a dozen species besides.
\end{abstract}

\section{Voice, Sound, Context}

On 18 January 1949, on the Australian Walkabout program, the national service of the Australian Broadcasting Commission (now Corporation; ABC) broadcast a radio documentary feature on the American-Australian Scientific Expedition to Arnhem Land. The title might have lacked imagination-it was called 'Expedition to Arnhem Land' - but it marked a critical moment in Australian media history, and an informed audition of this all-but-forgotten 'text' allows us to hear something of the way in which the Expedition was culturally located in postwar Australia. ${ }^{1}$ Most importantly (for this writer), it allows us to see and hear how a significant cultural actor of the day, the journalist Colin Simpson, grappled not only with the issues or 'problems' thrown up by the Expedition and his role in reporting it (not the least of these being the representation of Aboriginal culture), but also how an independent writer or journalist might position himself in relation to the $\mathrm{ABC}$ as a state-owned public cultural institution at a moment when those relationships were very much in active negotiation. In particular, this chapter explores the uneasy and, at the time, ill-defined relationships between writing and recording, between 'free' and written speech, and between the voice and other sound, in reporting and documenting events.

In this context, the 'wild sounds' - those being the sounds of the environment (both natural and human) recorded and incorporated into this documentary by Simpson - should be read as signal moments in Australian media history. With the exception of some extraordinary war reporting in the preceding

1 This was a repeat broadcast. The first took place on 30 November 1948. 
five years, sounds such as the recording labelled 'Bird life on a swamp on [sic] Arnhem Land 1948', the sound effect or 'SFX' invoked in the opening to this chapter (and referred to hereafter as 'Bird life'), had rarely been included in a documentary feature as 'texts' - as syntactical elements in a narrative - let alone as autonomous sonic objects. While today a sound recordist (working with a film crew, say) will refer to the ambient environmental sound that must be recorded on site after an interview or dialogue has been recorded as 'wild sound', in this discussion a more critically inflected idea is at play, as evoked by the radio-maker and sound studies scholar Virginia Madsen in her essay 'The call of the wild':

Sounds seem to rise up out of the depths and chaos of noise, mysteriously calling, summoning us to respond. Sound is a paradox. It is both effect and fact, both a virtuality (in the sense of a force) and an actuality - the consequence of movement in space; in an atmosphere, a milieu; of a source. Source and milieu cannot be separated... The being of soundstheir coming into presence-leads us to their mystery, their ability to act as marked figures within the noise of acoustic space, while at the same time appearing as if they are free of this space - purified, disembodied and metaphysical. Sound is, by nature, a detaching and transforming event, a mix between figure and ground, a re-sounding which always implies a medium: a 'flux in which figure and ground rub up against and transform each other' [as Marshall and Eric McLuhan described it]. ${ }^{2}$

Madsen's discussion of the 'virtuality' of recorded 'wild sound' is founded in a notion of fidelity that would not be achievable for a good 10 or 15 years after the 'Bird life' recording. So the audio documentation described here was made on the cusp of these developments, and is all the more important as a consequence. Their resonance, if you like, goes well beyond their indexical functionality.

In 1949, the radio 'documentary feature' was a novel formal category. Scripted 'talks' and various forms of radio drama had been core elements of ABC programming almost from the inception of the commission in $1932 .^{3}$ But the 'documentary feature'-particularly the type of program discussed here, involving recordings made in the field - was, in 1948, an almost new category. Indeed, it was only that year that a separate Features Department had been established within the ABC. The Australian Walkabout series was inaugurated in 1947 by Colin Simpson. ${ }^{4}$ Its defining quality was its reliance on facts; as the advertising explained, the program was 'Built upon Factual Happenings of

\footnotetext{
2 Madsen, V. 1999, 'The call of the wild', in M. Thomas (ed.), Uncertain Ground: Essays between art and nature, Art Gallery of New South Wales, Sydney, pp. 34-5.

3 For a comprehensive overview of the ABC's early development, see Inglis, K. 1983, This is the $A B C$ : The Australian Broadcasting Commission 1932-83, Melbourne University Press, Carlton, Vic.

4 Ibid., p. 164.
} 
Yesterday and To-day'. ${ }^{5}$ While 'Expedition to Arnhem Land' was researched and presented by Simpson, the credit of producer went to John Thompson, the other pioneering figure in the development of 'the feature'. Simpson recorded actuality for the program when he spent a fortnight at the Oenpelli (now Gunbalanya) base camp of the Expedition in late September and early October 1948. ${ }^{6}$ Simpson was accompanied on his Arnhem Land foray by Ray Giles, a sound engineer employed by the Postmaster General's Department (PMG), which, until 1964, provided technical services to the ABC.

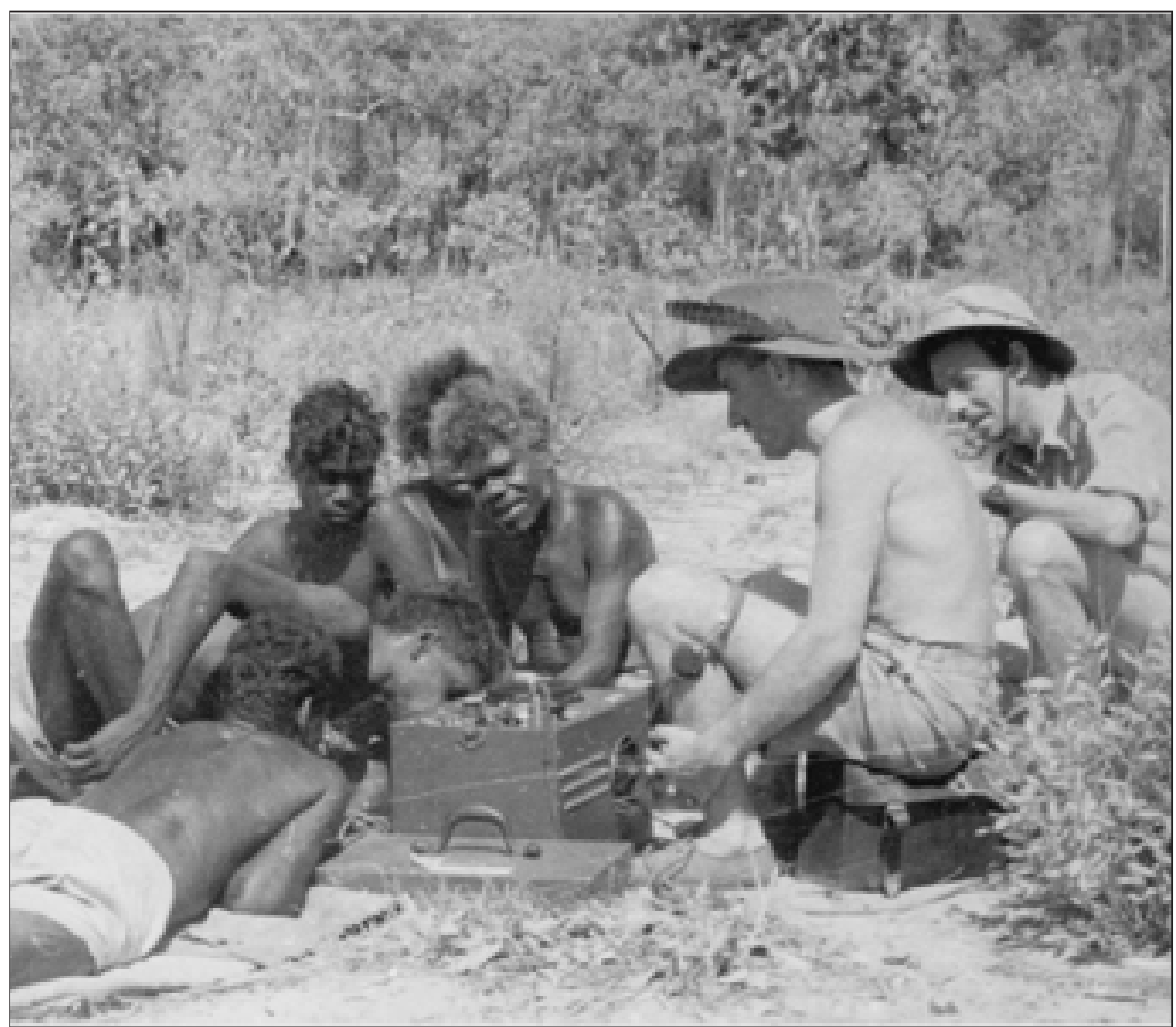

Figure 5.1 Recording session at Oenpelli (now Gunbalanya). Colin Simpson (far right), Raymond Giles and four unidentified men around the Pyrox Wire Recorder, 1948

Photograph by Howell Walker. By permission of the National Library of Australia. NLA MS5253, Box 99, Bag B.

5 Advertisement, $A B C$ Weekly [Sydney], 27 November 1948, p. 14.

6 Elsewhere in this volume, Barwick and Marett and Garde draw upon the work of Simpson and the material he gathered in Arnhem Land working with Ray Giles. 


\section{An Effect}

Spinning at $78 \mathrm{rpm}$, 'Bird life on a swamp on Arnhem Land 1948' is a bakelite rendering of an acoustic event, previously recorded onto a strand of magnetised steel wire. Simultaneously, it is an object of nostalgia and its opposite: an irruption of pure noise, a moment of lived experience. In play (spinning), it stands as a lacuna of wild sound, a moment of then opening onto the now, almost (but not quite) managing to be the moment it claims for itself. But listening carefully beyond the birds caught on the wire, we might also discern not simply the fleeting 'being something' of another place and another time, but also a media practice in transition.

The 'Bird life' recording is one of the many field recordings made by Giles under Simpson's direction whilst the duo was 'up north', only three of which were of environmental sound. The remainder (23 'sides' of $78 \mathrm{rpm}$ discs) were of Indigenous music and song. Elsewhere in this volume, Allan Marret and Linda Barwick address the music recordings and Murray Garde analyses the ceremony in detail. My concern is with the non-music recordings (including the broadcast feature itself), which I think of as a kind of archaeological site. Digging down, we might be able to show, or at lest infer, the critical significance of these recordings in Australian media and cultural history.

Through close audition of this recording - a sounding, if you like, to borrow a metaphor from marine navigation - we might perform a type of cultural mapping. In so doing, we can gain insight into a largely unexamined momentthe moment when an emerging media technology enabled the voice to displace the authority of the written word in broadcast media. Inter alia, I want to locate that moment biographically, and to reflect on some ideas about the national broadcaster and the construction of national identity in relation to the 1948 Expedition.

I hope to demonstrate the extraordinary impact Arnhem Land had on Colin Simpson, who found in it a kind of 'souvenir' of a paradise lost - a memento from an Edenic landscape, which he understood to be at risk of vanishing. I also want to suggest that the recording might serve as a souvenir of another kind of loss: the loss of a writer's 'voice'. The recording marks the moment when the authenticity of reportage is guaranteed not by authority of the witnessing writer, but rather by his (or her) capacity to refer to the recording. 


\section{Setting Out/Coming Home}

After his fortnight with the Expedition, Simpson went on to Melville Island, where he recorded a local ceremony, the Yoi, that formed the subject of another Australian Walkabout feature titled 'Island of Yoi', first broadcast on 4 January 1949 - a fortnight before the repeat of the Arnhem Land program. Simpson later wrote Adam in Ochre (1951), a best-selling book based on these experiences, which covers much of the same territory as the radio feature and comments extensively upon the recording process. $^{7}$

We thus have three documents to work between: the field recordings, the feature program, and the book. We can 'hear' Simpson's voice in each of its different registers - the voice of the independent writer and the voice of the contracted state broadcaster - and it is possible to trace the lines of authority accorded to voice, sound and written word. Through this triangulation of auditory and written texts, we can track the course of the recordings through the static of history.

Three copies of the complete set of recordings are known to exist: one is held by the University of Sydney, a second set is held by the Australian Institute of Aboriginal and Torres Strait Islander Studies (AIATSIS), and the third is kept in the Sound Effects Library of ABC Radio. They can be simultaneously regarded as objects of scholarly inquiry and research; as a cultural record; and as a set of working tools for the radio producer.

The distribution of the recordings into research collections alerts us to the $A B C$ 's self-consciousness as a state institution with expressly pedagogic and cultural responsibilities, created 'to develop a service to meet national needs and foster a national culture', an organisation that, in 1939 (after seven years of existence), could claim to have had 'beneficial influence upon Australian standards of thought'. ${ }^{8}$ In the pages of the $A B C$ Weekly, the Arnhem Land Expedition is discussed in terms of its scientific and national benefit. In addition to previewing the radio feature ('Scientists tell A.B.C. unit of curious findings in expedition to Arnhem Land'), there are several articles written by the members of the expedition detailing their activities. ${ }^{9}$ The $\mathrm{ABC}$ is not simply documenting or reporting upon a scientific expedition, but participating in the process of collecting, discussing and archiving materials for further study.

\footnotetext{
7 Simpson also prepared a script for another feature, describing the performance of key elements of the Wubarr ceremony, which on the advice of A. P. Elkin was never produced and broadcast. See Garde in this volume.

8 Australian Broadcasting Commission (ABC) 1939, The ABC Annual, Australian Broadcasting Commission, Sydney, pp. 6-7.

$9 A B C$ Weekly, 27 November 1948.
} 


\section{Going Walkabout}

The first edition of Australian Walkabout went to air on 15 May 1947, two weeks prior to the inauguration of the ABC's independent news service on 1 June. A full-page advertisement for Australian Walkabout in the 21 June edition of $A B C$ Weekly runs: 'Meet Old Pioneers...Hear Actual Voices of Australian Personalities...Hear Exciting Incidents from Australia's Past and Present.' In its publicity, the ABC describes 'Expedition to Arnhem Land' as 'the authentic story of the Mountford Expedition'. ${ }^{10}$

The claim to the authenticity and factuality of the ABC's feature programs was made repeatedly at this time - on air (in program presentation), in promotional material and in corporate reporting. Given the frequency with which 'authenticity' is invoked, it is difficult not to read into it some corporate anxiety as to the legitimacy of the claim. It might, however, also reflect the habits of Colin Simpson as a journalist best known for his previous role as editor of Fact, the weekly feature supplement of the Sydney Sun newspaper, in which role he had been instrumental in exposing the Ern Malley literary hoax in 1944-a fact that might be seen to add particular poignancy to Simpson's negotiation of 'authenticity'.11

The stated objective of Australian Walkabout was to portray 'the life and history of important Australian towns and districts against the background of national development' ${ }^{12}$ The $\mathrm{ABC}$ was at pains to assure listeners 'that the greatest care was taken to see that every detail was authentic, the material gathered at first hand by the special writers concerned'. ${ }^{13}$ Before moving to briefly consider the meanings of 'authenticity' in this context, it is important to look at the program series in which this feature was broadcast.

Today the term 'walkabout' seems to be used only by 'outback' tour operators and in describing the brief meet-the-people street walks of visiting royalty. While it might well be the case that 'to go walkabout' has lost much of its 'racist or disparaging overtones', applied to Indigenous Australians today, it would seem at best archaic and inadvertently offensive. ${ }^{14}$ In the 1940s and 1950s, it was a term that, despite its 'disparaging overtones', had significant cultural resonance. While describing the necessary peregrinations of Aborigines - to

\footnotetext{
10 ABC Weekly, 3 January 1949.

11 The story of the hoax was, fittingly, the subject of a 1959 radio documentary feature by John Thompson, in which Simpson appeared briefly. The full transcript can be found in Jacket: <http:jacketmagazine.com/17/ ern-thom.html>

12 Australian Broadcasting Commission (ABC) 1948, Annual Report, Australian Broadcasting Commission, Sydney.

13 Ibid.

14 Wilde, W. H., Hooton, J. and Andrews, B. (eds) 1994, The Oxford Companion to Australian Literature, Oxford University Press, Melbourne, p. 780.
} 
take part in ceremonial activity for instance - it carries with it the implication of unreliability, a casual attitude towards work and settlement. 'Walkabout' stands in contradistinction with settlement, with civilised life. Aborigines 'on walkabout' ceased to be stockmen or domestic help and became tribesmen and women - natives. While frequently invoked in this negative sense, it also implied the recognition of cultural difference: the recognition by white Australia that there were things that Aboriginal people did - and had to do - that 'we' did not understand. They were prepared to give up a job, reliable sources of food, the meagre comforts of the station settlement, to go off and do mysterious things: sorry business, men's business, women's business. 'Walkabout', then, hinted at a deeper way of knowing the country and its workings. The Macquarie Dictionary definition makes explicit the conflicts between white Australian culture and Aboriginal ways of knowing, describing walkabout 'as a period of wandering as a nomad, often as undertaken by Aborigines who feel the need to leave the place where they are in contact with white society, and return for spiritual refreshment to their traditional way of life'.$^{15}$

'Going walkabout', then, was seen as an expression of authentic Aboriginal culture, albeit that aspect of Indigenous culture that prevented 'them' from ever really settling down and being like 'us'. And as an authentic reflection of Aboriginality, 'going walkabout' was never fully explicable. In its vernacular use by white Australia, the idea of 'going walkabout' has also acquired a set of seductive and subversive meanings derived from its application to the nomadic habits of Indigenous Australians. Loading up the station wagon with swag and billy, suburban man and his family leave the bitumen (and civilisation) and head off 'outback'. Several weeks or months later, our happy wanderers return from this unstructured journey into the interior more knowledgeable, more at home with the country and with themselves, 'spiritually refreshed'. So, while there were numerous cartoons that depicted shifty blacks slinking back from walkabout, the word was affixed as a title to books and films with the connotation of journeying beyond the civilised world, travelling overland into knowledge. The international success of C. P. Mountford's 1941 ethnographic documentary Walkabout provided the kudos and contacts that enabled him to assemble and lead the 1948 Expedition to Arnhem Land. ${ }^{16}$

In choosing to name their new program Australian Walkabout, Colin Simpson and his colleagues in the newly formed Features Unit would have been aware of the multiple meanings and iterations of the term then in circulation. Indeed, the full-page advertisement referred to earlier uses of the image of a swagman

15 Macquarie Dictionary, 1991, (Second edition), The Macquarie Library, Sydney.

16 'New light on native art in Australia', Sydney Morning Herald, 21 August 1949, p. 2. See also May, this volume. 
as its logo. ${ }^{17}$ The 'swaggie' is the white Australian on perpetual walkabout, an unkempt if generally benign itinerant, restlessly on the move, avoiding settlement, shy of regular work. As a symbol of intractable independence, the swagman is a peculiarly Australian figure, entering national mythology via a song that has him stealing a sheep and, to avoid punishment, drowning himself.

As he is depicted in the advertisement for Walkabout, the swaggie, waltzing his 'matilda' (a vernacular term for his meagre bundle of possessions), is a nostalgic figure, a relic from the days of the gold rushes and pioneers. At the same time, it is difficult to imagine that Simpson would not also have been familiar with a more recent and less romantic image of the itinerant: the many thousands of men (and women) who took to the road ('on the wallaby') in search of work during the Great Depression.

\section{Waltzing the Wire Recorder}

The portability and reliability of recording equipment in the immediate postwar years enabled the program maker not simply to get out of the studio (they had been doing that for years) but to venture forth into remote places with relative ease. The idea of reporting the richness and complexity of life in the wide brown land obviously met with the state broadcaster's sense of high national purpose. This was congruent with an invigorated sense of national developmentespecially of the remote and sparsely populated north - in the aftermath of the Pacific War.

But there is also, I suspect, a hint of the feckless in calling this roving 'features' program Australian Walkabout. One of the implications of getting out and about is that we will hear the unruly voices of ordinary Australians talking about their extraordinary, yet to them ordinary, lives. But, the ABC assures us, every detail is bona fide; the risks of 'going walkabout' could be justified only by the resulting program's claim to authenticity. Listeners could be assured that not a lot of 'wild talk' would be allowed to leak out of the wire. After all, $\mathrm{ABC}$ announcers still wore evening dress, and speaking proper was all the go. Parcelled up with the dangerous suggestion of feral authenticity is an ambiguous gesture towards the Indigenous, partly as recuperation of the Aboriginal need to walk the land into being, and partly as a new claim on the part of white Australia to share in this ancient, nomadic way of knowing, to appropriate (or at least partake of) authenticity through the act of recording 'on walkabout'. That we might 'go walkabout' with the $\mathrm{ABC}$ in the name of national development

17 The Macquarie Dictionary cites the wanderings of the swagman as an instance of 'going walkabout'. 
further complicates the picture. There is no record of who actually came up with the name of the program, but the mix of the populist and the romantic with a slightly subversive subtext seems particularly 'Simpsonesque'.

The mixed signals about the nature and purpose of Australian Walkabout are audible in the opening sequence of 'Expedition to Arnhem Land': the tone of self-importance and cautious reassurance from the announcer, and then, from Charles Mountford, with his insistence upon the scientific purpose of the Expedition and the solemn invocation of the Commonwealth Government. The announcer enters on the back of a pompous and extended orchestral fanfare that cross-fades with the sound of didjeridu (one of the earliest known broadcasts of this instrument). The announcer notes that this exotic music was recorded in remote Arnhem Land, and then enjoins his listeners to attend to this authentic account of the "joint Commonwealth and National Geographic Society Expedition' and of 'what the scientists did', which is presented in a 'not too formal account'. The announcer throws to Simpson, who proceeds in a tone of weary seriousness (a tone at odds with the words he uses) to evoke beautifully the magical scene that greeted him at Oenpelli, before introducing a recording of an 'interview' with the expedition's Australian leader, C. P. Mountford. Asked to explain the purpose of the expedition, Mountford launches into a statement that is almost certainly read, in which he outlines the scientific brief of the Expedition (to collect samples of the flora and fauna and to study the habits of the natives) and its explicit nature as a government-backed venture, financed in part by the Department of Information. What Mountford does not make explicit is his status as a Department of Information employee, working in the department's Film Unit.

I might also note here that if not actually read (as I believe Mountford's responses are) then the answers to Simpson's questions were at least well rehearsed, as is made plain in an entry for 24 October 1948 in the journal of the Expedition's entomologist, John Bray:

Made my first recording for...the A.B.C. The two chaps, Colin Simpson, who does the spruiking, and his technician Ray Giles, are both very decent types. The $b /$ cast takes the form of a question and answer business, with all the answers well known beforehand, but not the actual question, so one has natural pauses to collect one's thoughts, but not much time. ${ }^{18}$

Bray goes on to note: 'Anyway, I had a good three minutes, mainly on insects, but a bit on walkabouts.'

18 J. E. Bray, 1948, Arnhem Land Expedition Journal, collection of Andrew Bray. I am grateful to Martin Thomas for drawing this to my attention. 


\section{Recording Eden}

The greatest care was taken to see that every detail was authentic, the material gathered at first hand by the special writers concerned.

- ABC Annual Report, 1949

The very public insistence by the $\mathrm{ABC}$ in its Annual Report on the 'greatest care' being taken by 'special writers' underscores both the importance the ABC placed on ensuring its feature programming was accurate and the privilege it accorded the writer-and writing - in vouchsafing its much vaunted authenticity. That privilege extended to being able to undertake extensive field trips far from the formalities of the ABC's offices in Sydney. It is easy to imagine Simpson's pleasure and sense of excitement as he made the journey north. With portable wire recorder in tow and notebook in hand, the ABC's 'special writer' was finally out of the office, on walkabout, to meet up with an international scientific expedition, the composition of which was an expression of the new postwar relationship with the United States. The authority of his reporting was affirmed by his reputation as a writer/reporter - an author. It would be several more years until the authorship of the radio documentary feature passed from the writer to the radio producer - a manipulator of recorded sound. This was the 'new kind of feature' pioneered by Simpson's colleague John Thompson. ${ }^{19}$

In many respects, this later development was made possible by another technical innovation. With the advent of audiotape in 1950, it became possible to edit sound recordings in much the same way as film. Wire recordings were not nearly as tractable and editing them was crude and imprecise. What role, then, for the sound recording in 'Expedition to Arnhem Land'?

There is no single answer to this question, for a set of conflicted relationships between writing and sound recording, and between writer and speaker, becomes evident in the opening moments of Simpson's feature. Questions of authority, authorship and authenticity are raised constantly, especially when we move from listening to 'Expedition to Arnhem Land' to reading Adam in Ochre.

Before returning to questions of recording and writing, it is necessary to expand upon the idea of the authentic, and to reflect upon our desire for it. One assumes the $\mathrm{ABC}$ had something like the dictionary definition of authenticity in mind: 'Real, actual, genuine: original, first-hand; really proceeding from its stated source, author, painter, etc. ${ }^{20}$ Yet authenticity is a much more culturally determined idea than the dictionaries suggest. The question of Indigenous authenticity, for instance, is one of Simpson's concerns, even though in the

19 Inglis, This is the $A B C$, p. 165.

20 The Shorter Oxford English Dictionary. 
radio feature Aborigines are present in the feature only as 'wild sound' leaking into the official discourse of the Expedition. In the book, the experience of Aboriginal authenticity is the organising principle, and the activities of the Expedition largely a means towards fulfilling a more ambitious pedagogic and personal goal: that of telling an original and originary story for contemporary Australia. Simpson writes: 'Not so much has been written about the northern tribes as, for instance, about the Arunta of the Centre; which is one reason for writing this book. Yet the Arnhem Lander can represent the prototype, the first man, the Adam of this land.' ${ }^{21}$

Here authenticity in the sense of the original is invoked, but, by extension, so is the post-Edenic state, the Fall into civilisation. But who has fallen from grace in Simpson's Eden? If 'Bird life on a swamp on Arnhem Land 1948' is in fact a souvenir from a lost paradise, the expulsion from paradise cannot be ignored.

Simpson was making a contribution to a vigorous public debate at a time when legislatures, experts (such as A. P. Elkin), and a diversity of interest groups negotiated the postwar shift in policy towards Aborigines, essentially from protection to assimilation. A changing sense of nationhood was part of the equation; the 1949 amendments to the Commonwealth Electoral Act gave the vote to Aboriginal and Islander servicemen and women, and, a fortnight after Simpson's documentary went to air, the Nationality and Citizenship Act came into effect, creating, for the first time, Australian citizens.

While assimilation was the clear thrust of government policy (as explicitly stated by Paul Hasluck, the new Minister for Territories, in 1951), the debate was by no means cut and dried. As the historian Anna Haebich and others have demonstrated, there was in this period considerable discussion about the practice of removing Aboriginal children from their families. ${ }^{22}$ While the idea of assimilation was strongly endorsed by bureaucrats and academics, the exact meaning of the term was also being discussed in the press and the legislature. There was a growing interest in Aboriginal art and culture in this period. In the public discourse, a clear division was emerging in the way Aborigines were imagined. On one hand, there were the 'real Aborigines' - 'full bloods' living more or less traditional lives in the remote north and centre of the country; and on the other, the 'half-castes' who lived in the settled districts (see Thomas on Gerald Blitner, this volume). One of the ironies of this bifurcation is that popular opinion denied 'real' (authentic) Aborigines citizenship while acknowledging their cultural integrity and the right to control their destiny on their traditional lands, while the 'half-castes' — the inauthentic Aborigines - might be granted

21 Simpson, C. 1951, Adam in Ochre: Inside Aboriginal Australia, Angus \& Robertson, Sydney, p. 7.

22 See Haebich, A. 2000, Broken Circles: Fragmenting Indigenous families 1800-2000, Fremantle Arts Centre Press, WA, chs 7 and 8. 
full citizenship, but denied their Aboriginality. This view enjoyed the support of political figures, of academics including Elkin, and of many supporters of Aboriginal rights. ${ }^{23}$ The Secretary of the Australian Aboriginal League argued in the Sydney Morning Herald that

the use of the term 'aborigines' confuses in the public mind the problem of the persons of mixed blood, who should be granted the privileges of the full citizens, with the problem of the real aborigines, those thousands of persons of full blood who are still living in tribal land under neartribal conditions. ${ }^{24}$

Simpson's take on this debate is complex. When broaching the subject in Adam in Ochre, he begins by asking if the Aborigines have fallen from grace. Has their contact with white society diminished their originality? At first, he assumes this is the case, but his later experience makes him question his initial impressions.

The old men Mountford brought back to the tent had been hoeing the mission's melon patch. They looked unimpressive, they looked dreadful in cast-offs of clothing and shapeless relics of felt hats. They sat down on the grass, folding themselves down in that slow and diffident way they have with white men, one wringing his nose out with his fingers, another coughing. I thought to myself, 'Nothing much can come of this'. I was judging by appearances, presuming that the old men had shed their validity as aborigines and put off their old culture because they had put on rags of white-man clothing and were taking hand-outs from the mission.

It was these old men and others they mustered who, transformed with paint and fervour, gave us the unforgettable performance of the... corroboree a few days later. ${ }^{25}$

In Adam in Ochre, Simpson essays a number of ways of approaching Aboriginal culture and the so-called 'Aboriginal problem'. From this distance, his attitudes can appear contradictory - he can be patronising while asserting the cultural and intellectual equality of white and black Australians - but his underlying commitment is clearly to encourage his fellow citizens to recognise the diversity and complexity of aboriginal culture, and to see the fundamental importance to Australian society of coming to terms with the history of Indigenous displacement and cultural destruction by European settlement. ${ }^{26}$

23 Elkin, A. P. 1949, 'Australia and the Aborigines', Sydney Morning Herald, 29 January.

24 Groves, H. S. 1949, 'Tribal life menaced', Letter to the Editor, Sydney Morning Herald, 8 September.

25 Simpson, Adam in Ochre, pp. 6-7.

26 Simpson claims credit for bringing together the composer John Antill and the painter William Constable with the idea of having a ballet created on an Aboriginal theme. The resulting Corroboree was a disappointment to Simpson: 'Through a lack of understanding and plain lack of knowledge, the choreographer completely missed the spirit of the real thing in a riot of baseless representationalism, full of incongruous and extraneous elements' (ibid., p. 607). 
To return to the Fall and the question of authenticity: the authentic being of the Arnhem Land Aborigines serves to remind us - the listener, the reader, the author - of the inauthentic nature of white, urban, civilised existence. Although never stated explicitly, this confrontation with our own inauthentic natureand the possibility of redemption through encountering the authentic in the landscape - is the key subtext of the book.

\section{Entering Eden}

In both the book and the radio documentary, Simpson's introduction evokes the idyllic setting in which he first encounters the Expedition members: the lagoon with its water lilies, the sacred mountain behind, the natives fishing at one end, the naked scientists bathing at the other. It is a scene sketched with great economy and skill, and Charles Mountford's rehearsed bureaucratic banalities (in the radio documentary) bring us down to earth with a thump. In the book, Simpson can tell the story his way, and he completes an extended version of the same introduction as follows:

In the lagoon at evening, when the last glow of the sun made satin of the water and the wind stood still, was the day's best hour. Down there at the big billabong mirroring Inyaluk, shared with the natives and the near birds no one turned to hunt, there was a feeling of being part of a quest that was wider and more real than anything you could seek for in a city [my emphasis], and there was no sense of urgency in need or time. There was a balm and essence I have not felt before or since. Others felt it, too. I remember Bob Miller, the ichthyologist, standing out there in the quiet water the evening before he had to leave Oenpelli and return to America, saying, 'This I am going to miss a great deal...' ${ }^{27}$

This is Eden invoked and evoked at a time when Arnhem Land 'bore a sinister reputation and was shunned by white men except for a few buffalo hunters, traders, missionaries, patrol officers and anthropologists'.$^{28}$

Simpson is equally romantic but more sentimental as he seeks to instruct his (primarily) white, urban readers in their own inauthenticity. Adam in Ochre recounts a personal journey that at least suggests the possibility of individual redemption or recuperation of an authentic being. One section of the book is a novella called 'Kakadu naked', which tells the story of 'Najanja, man of the Kakadu people' and his children. It is a love story that turns into a tragedy, told from an Aboriginal perspective. It concludes with the careless debauching

27 Simpson, Adam in Ochre, p. 10.

28 'Expeditions begin assembling', Sydney Morning Herald, 26 February 1948. 
of a young Kakadu woman by a white adventurer. We are presented with a truly nasty encounter between white and black Australia distinguished by hypocrisy and cruelty, and asked to judge the quality of civilised man against his (feminised) opposite, the primitive.

\section{Sounding Bloody}

In the book, Simpson makes clear both the personal impact of his journey and his central concern with coming to terms with the Aboriginal situation. How is this reconciled with his role as an $\mathrm{ABC}$ employee, a state functionary, out there reporting on this official Commonwealth-sponsored Expedition in the service of nation building? Something of the conflict that Simpson negotiates is discernible in the shift in the tone of his voice between Simpson-in-the-field and Simpson-in-the-studio. The effect is no doubt accentuated by the slippage in playback and recording speeds: the light, easy voice of the man on walkabout; the altogether more solemn, deliberate tones of the pipe-smoking narrator on duty in the studio. Simpson's studio script is economical, but his more lyrical reflections are suborned to the imperative to recount 'what the scientists did'. And what the scientists did is, by and large, less than riveting. Each interview adheres to much the same formula: description of task - 'I collect fish'; summary of findings - 'there are lots of fish'; and an anecdote - 'I found a funny fish'. On location, Simpson is enjoying himself, but also working to rule. He is interested, but the real work is going on in his head and in his diary, finding its fullest expression in the nuanced complexity and descriptive richness of the book.

And so the question again: what role for the sound recording? The wire recorder had allowed the writer to roam far and wide, to talk to real people, to capture the 'authentic' sounds of Australia, but the feature was still authored by writing, not by recording. In 'Expedition to Arnhem Land', we listen on the cusp between the authority of writing and the authenticity of (recorded) actuality. This is the moment when the contemporary radio feature is being born. Simpson was still essaying the written word; it was another 20 years until a distinctively 'radiophonic' essaying found its way onto the Australian airwaves. ${ }^{29}$

Let us attend more closely to the sound of Simpson in the studio- the 'inauthentic' Simpson perhaps-before turning to 'Bird life', and further exploration of the relationship between writing and recording.

On the radio, Simpson introduces his interview with the deputy leader of the Expedition, the American archaeologist Frank Setzler, by describing it as the

29 See Madsen, V. 2009, 'A radio d'auteur: the documentaire de creation of Kaye Mortley', Scan, vol. 6, no. 3, viewed 12 December 2009, <http://scan.net.au/scan/journal/display.php?journal_id=142> 
liveliest of our recorded interviews'. We then cut to the field recording: Simpson is describing Setzler entering the tent at the end of the working day, covered in dust, and emptying a haversack of found objects onto his work table. It is all done 'as live': 'here's Dr Frank Setzler now, he's covered in dust, he looks as black as his native helpers... he's emptying his bag of finds onto the table...[SFX: clattering stones].'

Then Simpson asks Setzler what he has been up to, and Setzler replies: 'wait a moment Colin, until I get this dust off.' It all sounds bright and enthusiastic.

But to the contemporary listener, there is something odd about this, the 'liveliest of our recorded interviews'. The quality that jars for our ears is that it is clearly rehearsed. You can imagine the scene: Simpson says to Setzler, 'First, I'll describe you coming in, then you put down the knapsack, and I'll ask you what you've been doing', and so on. In some cases, as with Mountford's recitation of the Expedition's history, Simpson's interview subjects read from prepared texts. I have no doubt that Simpson's reporting of the scenes is accurate, and the material he recorded on the wire proceeds from his inquiries. Simpson has simply chosen the best bits (or at least, those most appropriate to the needs of his $\mathrm{ABC}$ mission) from his conversations with people, and asked them to repeat them for the wire recorder. In effect, these semi-scripted re-enactments constitute a kind of 'writing for the recorder'. Simpson was by force of habit and faith a writer. Mostly, Simpson treats the recorder as something like a typewriter, a tool with which the writer transcribes his rough notes, turning them into reportage for public consumption. He does not appear to trust the recorder as an observing device in its own right, as capable of hearing beyond his own listening. He would not appear to acknowledge that he might in fact work with the wire (recording) in the same manner as he might rework his notes.

Curiously, it is precisely Simpson's treatment of the tape recorder as a notebook, which he later transcribes and then reworks as a writer, that allows us to explore the ambivalent nature of the author's relationship to the sound recording - and to the recording machine itself. An event described in great detail in the bookbut not included in the radio feature - serves to illustrate the point.

Simpson goes on a buffalo hunt with a number of Aborigines. Also present are Len Hillier, a professional buffalo hunter employed by the Oenpelli mission, and Aub Dunkley, one of the white mission employees. In Adam in Ochre, the hunt is described almost exclusively through quotation from, and comment upon, the recordings Simpson and Giles made. It is a story about recording and radio as much as it is about buffalo hunting. First, they set up to record the hunt:

We went across a narrow stretch of plain into a clump of paperbarks that came out like a peninsula on a sea of green rice-grass... Ray would 
stay on the truck with the wire recorder...I picked a paperbark...and from its fork I could see right out over the plain where some buffaloes were already grazing. We ran the microphone lead through a few tree tops to the tree I was in. I looped the mike on to a limb where I could let it hang...A wind was blowing, so I tied a handkerchief over the front of the mike, otherwise the wind comes in a low roar. Then I tested with Ray and, settling myself back in the fork of the paperbark, waited for the shoot-boys to come in sight with that good feeling of anticipated excitement. Maybe we'd get a recording that would have the listeners in the suburbs gripping the Genoa velvet of their lounge chairs. But it wasn't our day. ${ }^{30}$

The buffalo refused to come crashing through the paperbarks, so Simpson had no recourse but to provide a running commentary from his vantage point of the hunt taking place out on the plain. In the book, Simpson directly transcribes the recording, but inserts a number of observations that can be seen as Simpson-thewriter admonishing Simpson-the-speaker. In the book, he puts this commentary on his own speech in italics:

Ah. Over here - er-well, a shot buffalo is not down-he's charged at a horse - the horse jumps aside. The wounded buffalo stops, even from here he looks bullet stricken and bewildered. The horseman rides away, just a calm canter, about fifty yards, looking over his shoulder at the bull, still standing there. Now the shooter has dismounted, he's on foot (of course he's on foot, mug, if he's dismounted). The shooter walks towards the buffalo and now the buffalo (keep your voice down!) walks toward him, head lowered and-his - the shooter's rifle goes up - and he drops the buffalo with a shot between the eyes. (How the hell do you know at this distance whether it was between the eyes? Well where else... Get on with it! But there's nothing doing, except that the other buffaloes have got away). The rest of the buffaloes are racing for the paperbarks on the right - they'll make the timber - while all the shooters are across on the left... OK Ray, cut, you can switch off now. Was I working too close to the mike again and how did it sound-bloody? I'm coming down now, you can tell me. Sorry you couldn't see it from where you are. ${ }^{31}$

At one level, Simpson is simply allowing us behind the scenes, unveiling the clunky machinery of recording and the frailties of the reporter. But it is a passage that also seeks to undermine the authority of the 'live' recording and

30 Simpson, Adam in Ochre, p. 30.

31 Ibid., p. 31. 
Simpson's 'wild talk', his unwritten self. This spontaneous commentary might be authentic, true to the moment, but it lacks the authority of the written word, committed to paper after considered reflection.

\section{Coming into it Like a Child}

There is an incident later in the buffalo hunt that perfectly captures Simpson's acute ambivalence about the function of the recorder as a source of authority, a moment when that which is unrecordable - unsayable - is able to be written; a sharp illustration of the division between speech and writing, utterance and text. It also reveals the extent to which Simpson attributes to the recorder an element of agency, in much the same way we attribute agency to a gun in saying it 'goes off'.

Back to our buffalo hunt.

Given the extreme heat, the shooters prefer to cripple rather than kill the buffalo outright. They then leave the animal lying there, in the heat and in pain, until they can come back to skin it - in some cases, overnight. The buffalo is finally killed just before skinning: it is easier to skin a freshly killed carcass, and there is no risk of the beast rotting in the heat; a rotten skin is of no commercial value. Simpson finds the practice repugnant, and is determined to expose it as cruel.

When we got back to the waterhole near the camp Aub superintended the washing of the hides. They were dragged off the truck and into the water and left there to soak off the mud and the blood, and then they would be liberally salted to keep them. I got Aub to explain that on to the recorder which was on the truck, working off two six volt batteries.

'We'll go straight from there with a snap start,' I told Ray. I didn't like what I was going to do next, as I went ahead on [Ray's] nod.

'Mr Dunkley,' I said, 'have you lost any hides today in the heat?' I turned the mike to Aub.

'Yes, we've lost one that was left too long before skinning,' he said, coming into it like a child.

I lowered the mike and told Ray to cut, I couldn't do it cold.

'Aub, I'm going to ask you about leaving them alive until the next day. You represent the mission out here...' I looked at Len sitting in the truck.

'You can't ask him that,' Len said. There was no rancour in his voice. 
'No,' I said. 'I'll think that'll do, Aub. Thanks.' I told Ray to finish. I felt grateful to Len. It was as though he had knocked up my rifle when I was going to blast a sitting bird. ${ }^{32}$

It is an interesting moment, and our inquiry might take off in any number of directions. Let us follow the hunting metaphors for a moment. What starts off as entrapment, with the intention of capturing wild talk ('coming into it like a child') suddenly takes on the character of an act of unsportsmanlike aggression: 'It was as though he had knocked up my rifle when I was going to blast a sitting bird.' It is as though the act of recording Aub's unprepared answer parallels leaving the wounded buffalo out on the plain - an act of unnecessary cruelty. And yet Simpson the writer has little hesitation in giving us exactly the same information he could not bring himself to 'capture' on tape by interviewing Aub Dunkley.

Why?

Issues of journalistic ethics aside, I think the answer lies in Simpson's recognition of the fact that the recorder is indiscriminate in capturing 'raw speech'. Like the authenticity of the Aborigines, it approaches a state of nature, unmediated and preliterate, and at odds with his own belief in, and commitment to, the authority of writing and the civilising effect of the written word. It is an appropriately complex moment: contradictory, intensely felt, revelatory. The paradise of authenticity he evokes at the beginning of Adam in Ochre has its limits - nowhere more evident than when he writes that 'pre-literate people are sickeningly insensitive to animal suffering, and the first thing expected of any mission is that it should counteract cruelty, not countenance it as a means to an end - the end, in this case, being to earn funds to carry on its work of Christianising' ${ }^{33}$

I think here we find a key to understanding Simpson's ambivalence towards the sound recorder. The writer can choose his words, but the recorder is insensible to desire. Indiscriminate and amoral, it captures everything, unrestrained. It is a strangely primitive tool that the writer must keep continually in check, lest it reveal the violence in paradise - the violence of preliterate speech, of utterance. The risk of 'going walkabout' with the recorder is that the unsayable will be said, promiscuously authenticating the real with no care for the civilising effect - the discipline - of the (written) word.

While Simpson's abhorrence of what he perceives as cruelty delineates the limits of his romance with the real and original, it would be wrong to see him as some reactionary who resists sound recording - a kind of media Luddite. Instead, he 
is grappling with the problem of authorship in an emerging medium. Indeed, he continually reminds his reader that the writing of Adam in Ochre owes everything to the act of recording.

Simpson is also mindful of the way in which the recorder is fundamentally an extension of a larger cultural institution, which, in the immediate postwar years, was directly implicated in the task of 'national development'. There is a wonderful celebratory passage in Adam in Ochre where he looks 'back on the cavalcade of people I have seen carrying A.B.C. recording equipment':

I see the recorder-box and the label-gaudy Globite cases of mikes and vibrators and wires and spare parts being passed from an Indian taxidriver in Singapore to a Dusan or a Murat carrier in North Borneo who puts some of it in a round bark basket called a boongen and hoists it on his back.

The recorder passes from hand to hand through Asia and across Australia, until finally a 'Canberra technician sets it up before the Prime Minister' ${ }^{34}$

This makes a neat summary of Simpson's ABC career: a series of journeys to exotic places, ending in an audience with the Prime Minister. Simpson joined the ABC in 1947 to help establish the Features Department, and left in 1950, after the commission (somewhat regretfully it would appear) failed to renew his contract, choosing instead to spend the money on purchasing freelance contributions. ${ }^{35}$ Adam in Ochre was published the following year. Simpson parlayed his ABC experience into a very successful career as a writer of highly regarded travel and history books, the first three of which (the Adam series) draw directly upon his $\mathrm{ABC}$ travels - and, critically, on the recordings he made 'on duty'.

\section{Institutional Speech}

'All speech is on the side of the Law', writes Roland Barthes. The speaker/ teacher either accepts his role as authority - speaking clearly-or attempts to subvert it by 'speaking badly', correcting, adding, wavering. Finally, he argues, 'the choice is gloomy: conscientious functionary or free artist' ${ }^{36}$ We might hear the broadcast speech or radio talk of the period under discussion (when a 'talk' was given from a written text) as both confirming and complicating Barthes' assertion that 'writing begins at the point where speech becomes impossible'. The voices we hear can be either reading from prepared scripts or extemporising.

\footnotetext{
34 Ibid., p. 137.

35 Inglis, This is the $A B C$, p. 164.

36 Barthes, R. 1984, 'Writers, intellectuals, teachers', in Image, Music, Text, (trans. Stephen Heath), Flamingo, Oxford, p. 192.
} 
In either case, the voice is framed-authorised-by its institutional context: in this case, the ABC. The Simpson we hear in 'Expedition to Arnhem Land' and read about in Adam in Ochre is the writer negotiating the paradoxes of recording, but he is also attempting to reconcile his role as a broadcaster within an expressly pedagogic national institution - a role defined (until that moment) by formal speech - with his more strictly independent role as a writer. One of the paradoxes of the move from writing to extemporaneous speech initiated by Australian Walkabout is that it seeks to reverse the power relations sketched by Barthes. In letting Australians speak freely (more or less), the authority of the written talk is diminished. Australians talk back to the lecturer, albeit within a highly regulated context.

These are the paradoxes Simpson negotiates in his attempt to record (in writing and sound) the authentic experience of his journey to Arnhem Land. At Oenpelli, Simpson is almost the 'free artist', the writer 'on walkabout' from the $\mathrm{ABC}$, but the Pyrox wire recorder is both his excuse for being there and the source of his authority as agent of the state. It has an almost living presence. Is Simpson accompanying the recorder, or is the recorder accompanying Simpson? ${ }^{37}$

\section{The Morning of the Birds}

I have sought to locate Simpson in the midst of complex cultural and historical forces. We see and hear him negotiating competing discourses of authenticity and conflicting notions of authority; attempting to reconcile writing with speaking; and confronting the dilemma of Aboriginal existence in the Australia of 1948.

As is evident in his writing, all these problems engage him very personally. Yet this experience is largely inaudible in the radio program - heard only in the reluctance evident in Simpson's voice as he reads his narration, which might be read as discomfort with his role in the nation-building functions of Australian Walkabout. (On close listening to the studio presentation, you can detect the sound of traffic on the street outside the studio. This sonic leakage of the 'outside' into the acoustic sanctum of the studio would be regarded as intolerable in contemporary practice, but in this context it has a strongly poignant effect, placing Simpson behind a desk in a banal Sydney office, far from the exotic doings of his freer, recorded self.) Similarly, in the field recordings, Simpson might be enjoying himself in his rehearsed interviews with the scientists, but he is not giving much away either. Only in those brief moments when the recording breaks with the word and allows 'wild sound' to burst through do we

37 Simpson includes a description of the recorder, and its cost, in his extensive glossary to Adam in Ochre - a self-consciousness unlikely in contemporary radio reportage. 
begin to approach the effect Simpson sought when he described the 'listeners in the suburbs gripping the Genoa velvet of their lounge chairs'. These are the moments when recording takes over from writing - those rare radiophonic moments when Simpson allows sound, not scientists, to speak. ${ }^{38}$

The presentation (in the radio documentary) of the scene represented in the 'Bird life' recording is one such moment. Why does Simpson include it? Superficially, it is consistent with the program's pedagogic intent, and it provides audible evidence of the exotic location. But clearly it is not intended to engender the virtual presence that attends contemporary environmental sound recording. Such recordings depend for their effect upon both high fidelity and extended durations. ${ }^{39}$

In introducing the recording in his radio program, Simpson is restrained, despite offering a detailed description of the location and the mass of birds. He opens with the observation that ' $\mathrm{t}]$ he bird life in Arnhem Land is amazing'. This is in contrast with Adam in Ochre, in which the same scene is presented as the apotheosis of his Arnhem Land experience. He describes it in great detail in 'The morning of the birds' - a chapter close to the middle of the book.

One morning before dawn, Simpson sets off with four Aboriginal men towards the lagoon. The recording gear has already been set up in a hide at the water's edge the previous night:

The babel of birds came to us before we reached the nearest edge of the mile-long marshy lagoon. I have never seen such a sight as it was that morning. An empty stretch of water can be beautiful, but this was something beautifully alive. The multitude of birds across the expanse of water left few patches where they were not feeding or swimming or alighting or taking off. Yet, with all their movement, and all their cries and murmur vibrant in the air, there was serenity, as of a park pond made enormous, a sanctuary limited only by the flank of sandstone on our right and the far tall trees of the paperbark belt. Veils of mist were rising and wreathing away. The sky was pearly and the far scarps of sandstone beyond the trees stood up like unsubstantial walls in the soft light that made them mauve. There was no flush of sunrise yet across the water.

After some trepidation about leeches and the possibility of encountering crocodiles, Simpson and the Aborigines enter the water and begin slowly driving birds within range of the microphone.

38 Another such moment is the recording of the didjeridu. As far as I have been able to ascertain, this was the second time the sound of the didjeridu had been broadcast.

39 Madsen, V. 1995, 'Notes toward sound ecology', Essays in Sound, no. 2. 
The sun was coming up now and the water was shining. The sun gave the birds shadows and reflections. I was nearly out in the centre of the lagoon then and, more than ever, the air was alive with the sound. I waded on through the sunrise colours in the water, the birds rising before me, knowing that it was a morning that would be with me as long as I lived.

It was almost seven o' clock when I waded up to a little rocky islet, rolled a cigarette, and wrote some of it down...[I'm glad I did] because the notes have fixed impressions that might have blurred. For all [the birds] that had been flushed to the upper reaches there were still thousands down the lagoon and on either side. The top end had been crowded with birds for the best part of an hour. Ray should have some good sound. It was time to go right up and create the final sound we hoped would make a fine climax.

As I started wading the last stretches there were necks up everywhere; the geese, talking, talking, talking - here was that man again. If I wanted photographs, and I did, this was the time to use the camera, or it would be too late. I took it out of its case, the little Nagel that fits in the palm of my hand, and waded on a few more yards. I was raising the camera to shoot when my right sandshoe went slip in the mud and as I saved myself from falling the camera slipped out of my hand and plopped into the water. I whipped it straight up from the muddy bottom. I looked at it and the picture in front of me, a picture such as I shall never get again. Raising the dripping camera I looked at the picture through the viewer. Geese were rising in hundreds just in front of me, and the water was full of the reflections of geese flying. Knowing it was senseless to do so, I clicked the sodden shutter. I swore, but mechanically. The cursing chagrin I felt I should feel just wasn't there. The morning was too big for a thing like that to spoil. To complete the sound picture, which was the important thing, I quickened my pace. The thousands of birds between me and the hide all began to take the air, flapping and honking and calling and crying. More than I had ever anticipated was the surge of sound as their wings beat the air, almost a thunder of sound, a noise like a great cacophonous aerial host, still mounting to a crescendo beyond any crescendo expected as all the flocks wheeled back over my head and the sky was gone in a rushing, breath-taking pattern of black and white.

When it was over I walked out through the ankle deep shallows. The piping of the plovers at the edges and the little running snipe was like a twitter of sound underscoring a silence. I went up to the hide and Ray Giles came crawling out to meet me. 
'Did you get it all mate?'

'All you'll ever want and more,' he said. 'Come and listen to a bit of it back. It's wonderful.'

It was, too, even if we say so ourselves. We played back enough of the recording to know it was all there. The take-off was terrific. ${ }^{40}$

Compare that euphoric riff with his comment in the radio narration, where his joy at the crescendo of sound is reduced to 'toward the end of this recording you will hear hundreds of birds take off from the water'.

There are many things that could be said about the written narrative Simpson weaves around the moment of this recording. We might ponder the fact that although his camera has been destroyed, he must complete the ritual of the snapshot. It might appear that the sound recording is not a reliable witness to dawn in paradise. But we must also note that the whole sequence is articulated by - and through - the act of recording. The reader is in the end reminded that she cannot hear what Ray Giles and Simpson hear (or imagine they hear) off the wire: 'Come and listen...it's wonderful.'

There is a radical disjunction between the actual recording and the narrative Simpson weaves around it. A wire recording from 1948 is technically incapable of conveying the auditory richness and depth of Simpson's experience; it will not measure up to his memory. And it is precisely this fundamental inadequacy that defines 'Bird life on a swamp on Arnhem Land 1948' as a souvenir, rather than a 'true record' or document. As Susan Stewart writes, the 'souvenir must remain impoverished, and partial so that it can be supplemented by a narrative discourse, a narrative discourse which articulates the play of desire [without which] it would not function, that both attaches to its origins and creates a myth with regard to those origins' ${ }^{41}$ Stewart then goes on to argue that

the nostalgia of the souvenir plays in the distance between the present and an imagined, prelapsarian experience, experience as it might be 'directly lived'. The location of authenticity becomes whatever is distant to the present time and space; hence we can see the souvenir as attached to the antique and the exotic. ${ }^{42}$

40 Simpson, Adam in Ochre, pp. 70-3.

41 Stewart, S. 1993, On Longing: Narratives of the miniature, the gigantic, the souvenir, the collection, Duke University Press, Durham, NC, p. 136.

42 Ibid., p. 140. 
Notionally included to illustrate the prolific nature of the bird life in Arnhem Land, the recording functions as a souvenir of Arnhem Land's prelapsarian state, but also of the impossibility of Simpson's return to that state, figuratively and literally.

There is, however, another reading (hearing) of 'Bird life' that we might approach through attending to the difference between the way the recording is presented by the writer and by the state broadcaster. In Adam in Ochre, Simpson weaves an elaborate nostalgic narrative, a myth, around a recording that he presents to his radio audience with little more than the perfunctory 'the bird life in Arnhem Land is amazing'. Of course, the on-air Simpson is simply acting out his role as the narrator of a scientific documentary, broadcast with due authority by the ABC. But perhaps Simpson's restraint is also an acknowledgment of the failure of the recording to live up to his memory of the experience, a fear that by the time it passes through the ether and emerges from the speakers of Radiograms and Radiolas around the country, this recording too will fail to 'have the listeners in the suburbs gripping the Genoa velvet of their lounge chairs'. If this is Simpson's fear, he was both right and wrong.

In a radio program constructed almost entirely from various types of writing, the sudden opening onto the natural world represented by 'Bird life' is the exception, the irruption. Its brief presence serves to subvert the carefully constructed discourse of scientific inquiry. Its signal is its noise - not just the noise of all those birds, but the noise of the wire recorder itself, and the disc cutter and the playback turntable. The recording lacks the fidelity Simpson heard listening back to the original recording with Ray Giles ('it's wonderful'), and it lacks the authorising (and organising) narrative of the interviews. Almost despite himself, Simpson has offered something more than a nostalgic souvenir of the 'real' world to which words - culture - can only refer. Because it is only sound, not 'writing-with-the-recorder', 'Bird life' - a recording of birds and other noise - becomes an instance of the 'becoming', the being in real time that is sound. We hear it as an irruption of the 'now' into a carefully ordered assembly of (written) sound documents. As a sound effect, 'Bird life' refuses to be a souvenir because of its presence in the real time of now; sound is inherently incapable of being souvenired because it is only ever in the present. Referred to in a book, the recording is the occasion for a glorious evocation of dawn in paradise. Replayed in a studio, it fails to measure up to the myth and insists on its presence in the moment of audition.

'Bird life on a swamp on Arnhem Land 1948' also momentarily resolves the dilemma of speaking on the radio for the writer: it blows away all speech. And in doing so, it is the one moment when Simpson manages to step aside from Barthes' 'gloomy choice' between 'conscientious functionary or free artist'. Perhaps if he had had the opportunity to explore the 'sound effect', Simpson 
might have found himself relying less on the words and more on the sound. Certainly, his (very successful) post-ABC career is a reminder that the happy life of the 'free artist' is more usually built upon compromises. After completing his Adam series, Simpson went on to write popular guides to exotic cultures and difficult countries - roaming from Japan to the remote republics of the USSR. Even this market-driven independence was provisional: he wrote a sponsored history of the Ampol oil company, Show Me A Mountain, and between book projects worked in advertising.

There is, however, another sense in which 'Bird life' is indeed a souvenir of a 'lost Eden', not so much of Simpson's much desired state of authenticity, but from a point when the authority of reporting shifted from the writer to the recorder. Going on 'walkabout' with the wire recorder, Simpson inadvertently became the author of another kind of loss: while radio listeners began to hear the sounding world in all its acoustic richness, radio writers ceded (at least some of) their authority to the recorder. It was more than a decade until John Thompson and those who followed began to fully understand the critical and creative possibilities of 'writing on tape'. In the meantime, Colin Simpson left the sound recorder behind and stayed with what he knew best: the written word.

Despite his ambivalence about it, the recording that Simpson brought back was also a souvenir from the future - a crude pre-echo of the extended, highly accurate environmental recordings that are now the stock in trade not only of documentary makers but also of whole new categories of 'earwitnesses': sound designers, audio artists, composers of ambient music. ${ }^{43}$ Enter any Australian Geographic store and you will be immersed in richly detailed environmental sound. As likely as not, the landscape thus evoked will be that of some remote northern wilderness - dawn on a lagoon perhaps?

43 See Madsen, 'The call of the wild'. 